\section{Mind and brain}

\section{DEAR SIRS}

The relation of the mind to the brain is a conundrum that should concern psychiatrists and I am delighted that Peter O'Hara has taken the trouble to put his thoughts about it down on paper (Bulletin, October 1985, 9, 195-196) and that you have published them. However I think that it is sad that none of the extensive philosophical analyses of this problem (including the most recent series of Reith lectures) has been alluded to in the paper. The consequence of this is that O'Hara adopts a particular philosophical stance, behaviourism, which although particularly congenial to people who have been educated within the scientific tradition prevailing in psychiatry, certainly does not have all the answers (see, for example, Teichman ${ }^{1}$ for a short overview of this and other matters to be referred to later in this letter).

Another reason for regret over his omission of other people's views is that he has thereby missed out on one of the most important methods of philosophical analysis, debate. In the spirit of debate, I would like to make some comments on his paper. Although I do not propose a philosophical position myself, I do prefigure what preliminary work is, in my view, necessary. I suggest that this involves the establishment of a basis of knowledge which extends beyond knowlege about material things and thus involves the unlearning of some of the philosophical presumptions that many of us have absorbed with our physics and our anatomy.

O'Hara proposes that a description of different 'levels' is a useful one to be applied to the mind-brain problem. The use of this architectural metaphor is a common one in the neurosciences, and it seems to be readily applicable to, for example, the relation of molecular and cellular biology when it is clear that molecules are constituents of cells and thus must comprise a lower level. However when this language is applied to 'neuron function' and 'mental description' it is not at all apparent which is the lower level. Which is the smaller unit, a tiny wish or a cerebral hemisphere? Surely these are different kinds of things. I think that by using this language he is pre-judging his conclusion, which he self-effacingly states in the subjunctive, that 'a complete description of the mind' may eventually be written in terms of 'chunks of neurons'.

O'Hara provides two analogies of what he means by level. One is based on the properties of individual gas molecules and one based on computers. The application of both of these analogies is, unfortunately, obscured by mistakes. He seems to have got his computer terminology a bit wrong, but if he means a higher-level language by 'compiler language', then it is not true to say that 'there is no simple relation between words in a compiler language [sic] and numbers in machine code'. It is this very relationship which compiler or assembler programs exploit to allow programs written in higher-level languages to run.

O'Hara's gas example is a more interesting one, in that he uses it to show how "in chunking, determinism is lost'. Unfortunately for him, his analogy suggests quite the opposite. It is the property of individual gas molecules which is probabilistic, not the system, as O'Hara maintains. A mass of gas obeys laws governing the relationship of temperature, pressure and volume which are the very paradigm of determinacy.

O'Hara is right to suppose that aggregates have properties that single elements do not. His extended account of an embryological simulation is not really necessary to convince us of that although it does bring out the point, made so well by Ryle, that it does not make sense to say, in connection of a coat of cells, 'Which one is the coat?'. 'Coating something' will therefore do as an emergent property of an aggregate of cells and is an example of a 'higher level description' which is instantiated in a certain 'chunk' of cells. However coating behaviour is just as causally determined as the individual behaviour of cells. Complexity introduces extra links and branches in the causal chain, but it does not introduce uncaused events. However difficult it would be in practice to determine the behaviour of 'chunks' of neurons, this behaviour would be determined (O'Hara's occasional use of chunking to refer to the 'chunking of descriptions' does not alter this: a description of the process of coating something uses the language of cause and effect, too).

O'Hara has celebrated company in thus rejocting reductionism. Fodor ${ }^{2}$ summarises an extensive argument of this point in this way 'I am suggesting, roughly, that there are special sciences [in which Fodor includes psychology]... because of the way that the world is put together: not all the kinds (not all the classes of things and events about which there are important, counterfactual supporting generalizations to make) are, or correspond to, physical kinds' (Fodor, p. 24). ${ }^{2}$ However reductionism exerts as strong a pull as behaviourism on alumni of the science sixth form however, and O'Hara follows his exposition of Fodorian emergentism by asserting that a 'nuclear physicist' could in theory 'provide a highly deterministic account of a person's behaviour'. If O'Hara means 'determinate' by 'highly deterministic' and not 'a pretty good prediction' then this statement is plainly inconsistent with his previous and subsequent statements about levels.

I think I am reading O'Hara fairly in supposing that the physicist's self-description is a temporary aberration, and that his overall position is similar to that of Fodor who rhetorically asks 'Why, in short, should not the kind predicates of the special sciences cross-classify [sic] the physical natural kinds?' and later 'If science is to be unified, then all such taxonomies must apply to the same things [sic]. If physics is to be basic science, then each of these things had better be a physical thing' (Fodor, p. 25). ${ }^{2}$

O'Hara seems to me to be taking a similar materialist position. However his brief dip into epiphenomenalism, a doctrine which holds that 'all mental events are the effects of physical events but never the causes of either physical or mental events' 3 suggests that he is not entirely happy with the Artificial Inteligence version of materialism. 
One of the classical difficulties for the materialist position has been determinism. If all my behaviour is caused, then what am I to make of the statement 'I choose to go on with this sentence?'. O'Hara's slip about the gas laws enabled him to introduce indeterminacy into higher level descriptions but, as I have argued, this was a slip and no such facile move is really available. O'Hara seems to be making his discomfort with his own position clear in the last paragraph when the same problem resurfaces, in the shape of the relation of computer to minds. O'Hara here assumes that predictability is a necessary condition of rationality, and goes so far as to say that computers can be rational. Whilst I can see that this position is consistent with O'Hara's argument, it leads to conclusions that are so counter-intuitive that that argument is invalidated. Anyone who uses computers knows that they are, in between maintenance calls, predictable: but also that they are unutterably, stiflingly stupid. Anyone who knows people knows that the effects of unreason may be quite predictable, but that the effects of reason are often gloriously unpredictable.

The problem here is that O'Hara seems to take account only of some of what I take to be knowledge. I do not take other people, or myself, to be wonderful machines. Nor have I found out about my mind by abstraction from lower level descriptions in terms of the brain and its constituents. $\mathrm{I}$ echo Wittgenstein in saying ' $\mathrm{My}$ attitude towards him is as towards a Soul: I am not of the opinion that he has a Soul' (Wittgenstein, p. 178e). ${ }^{4}$ My knowledge of mental phenomena is quite as basic and inviolate as my knowledge of the behaviour of billiard balls and inclined planes.

At this moment in the brain sciences there appears to be no means of making all my knowledge consistent (see Armstrong \& Malcolm ${ }^{5}$ for a recent debate). I have been enjoined during my secondary education to suppose that 'scientific' meant correct and that the rest was something unreliable called 'intuition'. Moreover I have been taught that science was based on things that could be seen, touched, heard or smelt. Theories which could be instantiated in such things, or 'properties', 'fields', 'forces', etc. which affected such things constituted proper science. However the implication that knowledge is restricted to such things seems to me to be ill-founded. I can doubt the evidence of my senses just as readily as I can doubt my assumptions about other minds. Moreover any appeal to the efficacy of the brain sciences in understanding human behaviour could be countered by the greater usefulness of such mentalistic predicates as 'ambition', 'desire' and 'motive'.

O'Hara's article is a heartwarming attempt to incorporate something of the human in his biology, and not to accept the need, as many of us do, to put on our science when we arrive at work, and doff it when we leave. I do not regret his attempt to find a rational way of thinking about 'higher mental function' but only that it was not sufficiently radical. I wish that he had started from what he knew and not what he thought it was acceptable to say that he knew.

The University Hospital

Digby TANTaM

of South Manchester

West Didsbury, Manchester

REPERENCES

${ }^{1}$ Talcrman, J. (1974) The Mind and the Soul. London: Routledge \& Kegan Paul.

${ }^{2}$ Fodor, J. A. (1975) The Language of Thought. New York: Thomas Y. Crowell.

${ }^{3}$ Fuew, A. (1979) Dictionary of Philosophy. London: Pan.

"Wirtgensten, L. (1953) Philosophical Investigations. Third Edition (translated and edited by G. E. M. Anscombe) publ. 1967. Oxford: Basil Blackwell.

${ }^{5}$ Armstrong, D. M. \& Malcoly, N. (1984) Consciousmess and Causality. Oxford: Basil Blackwell.

\section{Dear Sirs}

I was very interested to read Dr O'Hara's article 'A Satisfactory Science of Mind and the Connection Between Mind Science and Brain Science'. The parallels drawn between computer operations and the brain are illuminating but there are some qualitative differences which could be further expanded and I wondered if, as a psychiatrist with a hobbyist interest in electronics since my youth, I might be permitted to make a few observations.

One is that computers at present are basically serial devices operating at a high speed of often several million operations a second on a relatively small number, typically between eight and 64 , of bits of data at a time with the electronic elements functioning generally as binary switches. The brain on the other hand has a much larger number of more complex elements operating much more slowly with action potentials taking a millisecond or so and with a greater degree of parallel processing. In addition neurones are not simple binary switches but perform a much more complex process of analogue integration of excitatory and inhibitory impulses from hundreds of other cells and then frequency modulate the cell firing rate as the output. In addition, of course, they are subject to further modulatory processes through general neurotransmitter levels and doubtless other factors we don't yet know about and the functioning elements of the brain are thus orders of magnitude more complex than a theoretical binary switch.

I was, however, interested in the discussions of the definition of an epiphenomenon and the ideas that low level information may often have little simple connection with the higher level patterns of which it is a part. It seems unlikely that the brain generally stores information with a direct one to one correspondence between the physical elements and the bits of data as in a present day computer. It is possible, however, that the states of many individual elements together contribute towards the storage of a piece of information and there are certain physical and mathematical processes which suggest analogies as to how this 